\title{
Zinc Supplementation Prevents the Complications of COVID-19 Infection in Cancer Patients
}

\author{
Samir Derouiche ${ }^{1,2}$
}

${ }^{1}$ Department of Cellular and Molecular Biology, Faculty of Natural and Life Sciences, El-Oued University, El Oued, Algeria. ${ }^{2}$ Laboratory of Biodiversity and Application of Biotechnology in the Agricultural Field, Faculty of Natural and Life Sciences, University of El Oued, Algeria.

\begin{abstract}
Novel coronavirus" SARS-CoV-2 is rapidly spreading worldwide with a significant mortality rate. In the crisis of COVID-19, cancer patients are seen as a very weak group and this is because of their weakened immune system and hence we aim in this research to show the importance of zinc as a buffer against cancer in COVID-19 for cancer patients. Zinc is an essential trace element that is crucial for growth, development, and the maintenance of immune function. zinc supplementation decreased and generation of inflammatory cytokines. zinc supplementation should have beneficial effects on cancer by decreasing oxidative stress, angiogenesis and induction of inflammatory cytokines while increasing apoptosis in cancer cells. zinc supplementation implemented to improve the antiviral response and systemic immunity in patients with cancer diseases. With the multiple doses approved from zinc, we suggest that there be an supplement in zinc by $50 \mathrm{mg} /$ day for three month with each treatment for cancer patients, in order to strengthen the immune system to prevent the serious effects of COVID19 infection.
\end{abstract}

Keywords: COVID-19- Cancer diseases- Zinc supplementation- Immune system

Asian Pac J Cancer Care, 5 (Suppl 1), 131-141

\section{Introduction}

Novel coronavirus" SARS-CoV-2 is rapidly spreading worldwide with a significant mortality rateSARS-CoV-2 is a new coronavirus called acute respiratory syndrome, and has been identified to be the cause of pneumonia [1]. In the COVID- 19 crisis, cancer patients are seen as a very vulnerable group [2]. As many studies have shown that patients with cancer have a higher risk of severe clinical events than those without cancer.However, many of the critical issues regarding treatment principles for cancer patients with COVID-19 remain unclear [3]. Trace minerals, especially zn $(\mathrm{Zn})$, have a very prominent role in various physiological and pathological aspects, which has been proven widely in recent years [4]. Zinc is an essential component that plays important roles in various biochemical reactions in many biological systems [5] such as its role as an anti-oxidant due to its being an cofactors of the superoxide dismutase (SOD) enzyme, this enzyme plays an important role in protecting the organism from oxidative stress, thus preventing the onset and development of tumor events [6]. Oxidative stress
Submission Date: 05/10/2020Ａcceptance Date: 06/28/2020

Corresponding Author:

Dr. Samir Derouiche

Department of Cellular and Molecular Biology, Faculty of Natural and Life Sciences, El-Oued University, El Oued, Algeria. ${ }^{2}$ Laboratory of

Biodiversity and Application of Biotechnology in the Agricultural Field, Faculty of Natural and Life Sciences, University of El Oued, Algeria.

Email: dersamebio@gmail.com 
risk of developing an COVID-19 epidemic viral more than others [11]. Which proves that patients with cancer are susceptible to infection with viruses, a study completed during the influenza A (H1N1) pandemic of 2009, where the results confirm that patients with cancer have cases of pneumonia by $(66 \%)$ more than others, and that the death rate among patients Cancer was higher (18.5\%) after 30 days compared to the general population [12]. One of the mechanisms of immune response against COVID19 is the cytokine release syndrome (CRS) which seems to affect patients with severe conditions [13]. Since lymphocytopenia is often seen in severe COVID-19 patients, the CRS caused by SARS-CoV-2 virus has to be mediated by leukocytes other than T cells, as in patients receiving CAR-T therapy; a high WBC-count is common, suggesting it, in association with lymphocytopenia, as a differential diagnostic criterion for COVID-19 [14]. In light of the pandemic of COVID-19, which overcame the health systems of countries, which threatens the health of cancer patients from two sides, either in terms of postponing treatment appointments, which is a risk to patients and increases the development of the disease [15], or either cancer patients can be called to hospitals and here the risk of infection and infection with COVID-19 increases [16].

\section{Role of zinc in immune system}

Zinc is vital for normal development and function of cells mediating innate immunity, NK cells and neutrophils [17]. Zinc deficiency affects multiple aspects of the immune system, from the barrier of the skin to gene regulation within lymphocytes [18]. The importance of zinc for proper immune function is best observed in zinc-deficient individuals. Zinc deficiency affects Phagocytosis, intracellular killing, and cytokine production and also the growth and function of $\mathrm{T}$ and B cells [19]. The development of acquired immunity is affected also by zinc deficiency through preventing both the outgrowth and certain functions of T lymphocytes such as activation, Th1 cytokine production, and B lymphocyte help [20]. Likewise, B lymphocyte development and antibody production, particularly immunoglobulin $\mathrm{G}$, is compromised. Zinc deficiency adversely affects the macrophage, which a pivotal cell in many immunologic functions, which can dysregulate intracellular killing, cytokine production, and phagocytosis [21]. Patients with zinc deficiency show symptoms in the immune system such as a decline in the number of lymphocytes, especially helper $\mathrm{T}$ cells with an increase in cytotoxic $\mathrm{T}$ cells and monocyte cytotoxicity, with reduced activity of natural killer (NK) cell [22]. The immunologic mechanisms whereby zinc modulates increased susceptibility to infection have been studied for several decades. The influence of zinc on viral infections depends on zinc status at baseline measurement, zinc supplementation concentration and frequency, zinc species and age [23].

Zinc in cancer disease

Since many studies focus on the causes and treatment of breast cancer, but still many important and unknown elements have a role in this disease [24], including the role of trace elements that play important roles in biological processes related to breast cancer, including zinc, which is a very important component that is active as an element [25]. It is essential in activating many of the enzymes involved in the synthesis of DNA and RNA, where many studies indicate that low levels of zinc in the blood are diagnosed for many malignant diseases, including cancerous diseases [26]. Zinc has been implicated in mediating apoptotic cell death. Both indirect and direct apoptotic effects of zinc have been demonstrated in cancerous cells [27], which illustrate that zinc active cell growth arrest at $\mathrm{G} 2 / \mathrm{M}$ according to the dose used. zinc has been attributed also in inducing the expression of $\mathrm{p} 21$, a cyclin-dependant kinase inhibitor known to govern cell progression at this phase [28]. Changes in blood zinc has been found in lymphoproliferative disorders as well as in breast, lung and gastrointestinal tumors [29]. Research indicates that the concentrations of zinc in the serum or plasma are low in people with cancer [30], which is consistent with severals study, which confirms that there is a strong relationship between low levels of zinc and cancer [31-32].

\section{Predictable effects of zinc supplementation}

It has been proven that zinc deficiency is the cause of many imbalances in the body in terms of slowed growth or susceptibility to disease, through many studies conducted on humans and animals [33], but a zinc supplement can correct these imbalances and is also useful for resistance against severe recidivistic infections or aging disease [34]. Zinc has been shown to have important therapeutic effects, such as its role in acute diarrhea, intestinal dermatitis [35] and its therapeutic role against aging diseases such as prevention of blindness in patients with macular degeneration as well as its role in relieving colds [36]. Zinc also enhances the up-regulation of A20 mRNA in HL-60 cells (promyelocytic leukemia cell line), which decreases NF- $\kappa$ B activation, IL- $1 \beta$ and and IL- 8 leading to decreased gene expression and generation of tumor necrosis factor- $\alpha$ (TNF- $\alpha$ ) [37]. On the other hand, zinc supplementation in young people and the elderly is very important in reducing oxidative stress and generating inflammatory cytokines, which allows the prevention of several diseases [38]. Also, zinc supplementation works to reduce vascular generation and induce inflammatory cytokines, which reflects the beneficial effects of zinc against cancers [39]. It has been clinically discovered that zinc supplementation has a primary role in inhibiting rhinovirus 3C protease and viral replication [40].

\section{Therapeutic doses of zinc}

The total zinc content in the human body amounts to 2-4 g, with a plasma concentration of $12-16 \mu \mathrm{M}$ [41]. The average adult requires approximately 8 to $11 \mathrm{mg}$ of zinc per. The use of zinc as a treatment with a studied dose can have a positive effect against chronic and acute viral infections and also can reduce the symptoms associated with this infection [42], either by activating the immune response in patients who suffer from zinc deficiency, 
or using a zinc supplement as a protective factor to inhibit viral replication or infection-related symptoms [43]. In a study conducted on rats, it was proven that doubling the zinc ratio five times over the normal value in food reduces the effects of oxidative stress in the testicles caused by diabetes [44]. The use of a zinc supplement at a dose of $10 \mathrm{mg}$ with 6 times / week for 6 months a significant decrease in the prevalence malaria with $22 \%$ fewer fever episodes than the placebo group [45]. In a clinical trial conducted on children, it proved that the use of supplemental zinc at a dose of $20 \mathrm{mg}$ / day reduced the duration of their pneumonia, which contributed to reducing the length of their stay in the hospital [46]. On the other hand, a number of researchers confirmed that the use of routine zinc supplements for a period of three months had a positive effect In reducing the severity of infections of the lower respiratory tract in children as well [47]. Also, in another study, it was pointed out that the great benefits of zinc supplements that are taken daily at a dose of $20 \mathrm{mg}$ to prevent infection and reduce viral infections in healthy older adults [48]. Several analyzes of the results of previous studies have shown that oral zinc supplementation reduces the incidence of acute respiratory infections by $35 \%$, reduces the duration of influenza-like symptoms by about two days, and also increases the rates of recovery among patients. Also, several other studies conducted in the United States India, South Africa and Peru demonstrated the positive effect of zinc supplementation, whose dose ranged from $20 \mathrm{mg} /$ week to $92 \mathrm{mg} /$ day [49-50]. Using a high dose $(1 \mathrm{mg} / \mathrm{kg})$ of zinc as a supplement can improve several symptoms such as diarrhea, weight loss, frequent viral and bacterial infection, skin inflammation, hair loss and neuropsychiatric disorders [51]. On the other hand, common cold symptoms can be reduced by taking zinc supplements at a dose of more than $75 \mathrm{mg}$ / day in healthy people [52]. However, excessive use of zinc has undesirable effects such as low copper level, low iron function, red blood cell abnormalities, decreased neutrophils and decreased immune function by consuming zinc for long periods at doses ranging from $50-150 \mathrm{mg} /$ day [53].

In conclusion, with the multiple doses approved from zinc, we suggest that there be an supplement in zinc by 50 $\mathrm{mg}$ / day for three month with each treatment for cancer patients, in order to strengthen the immune system to prevent the serious effects of COVID19 infection.

\section{Conflicts of Interest}

The authors declare no conflicts of interest.

\section{References}

1. Zheng J. SARS-CoV-2: an Emerging Coronavirus that Causes a Global Threat. International Journal of Biological Sciences. 2020;16(10):1678-1685. https://doi.org/10.7150/ ijbs. 45053

2. Moujaess E, Kourie HR, Ghosn M. Cancer patients and research during COVID-19 pandemic: A systematic review of current evidence. Critical Reviews in Oncology/ Hematology. 2020 06;150:102972. https://doi.org/10.1016/j. critrevonc.2020.102972

3. Spicer J, Chamberlain C, Papa S. Provision of cancer care during the COVID-19 pandemic. Nature Reviews Clinical Oncology. 202004 15;17(6):329-331. https://doi. org/10.1038/s41571-020-0370-6

4. López-Alonso M. Trace Minerals and Livestock: Not Too Much Not Too Little. ISRN Veterinary Science. 2012;2012:1-18. https://doi.org/10.5402/2012/704825

5. Derouiche S, Manel D, Kawther A. Beneficial Effect of Zinc on diabetes induced kidney damage and liver stress oxidative in rats. JOURNAL OF ADVANCES IN BIOLOGY. 2017 04 17;10(1):2050-2055. https://doi.org/10.24297/jab. v10i1.6022

6. Birben E, Sahiner UM, Sackesen C, Erzurum S, Kalayci O. Oxidative Stress and Antioxidant Defense. World Allergy Organization Journal. 2012 01;5(1):9-19. https://doi. org/10.1097/wox.0b013e3182439613

7. Derouiche S, Djouadi A. An evaluation of stress oxidative and serum electrolytes in female hypothyroid patients. Int $\mathrm{J}$ Biol Med Res. 2017;8(1):5861-5.

8. Grattan BJ, Freake HC. Zinc and Cancer: Implications for LIV-1 in Breast Cancer. Nutrients. 201207 04;4(7):648-675. https://doi.org/10.3390/nu4070648

9. Maywald M, Wessels I, Rink L. Zinc Signals and Immunity. International Journal of Molecular Sciences. 2017 Oct 24;18(10):2222. https://doi.org/10.3390/ijms18102222

10. Pothuri B, Alvarez Secord A, Armstrong DK, Chan J, Fader AN, Huh W, Kesterson J, Liu JF, Moore K, Westin SN, Naumann RW. Anti-cancer therapy and clinical trial considerations for gynecologic oncology patients during the COVID-19 pandemic crisis. Gynecologic Oncology. 2020 04;. https://doi.org/10.1016/j.ygyno.2020.04.694

11. Curigliano G, Cardoso MJ, Poortmans P, Gentilini O, Pravettoni G, Mazzocco K, Houssami N, Pagani O, Senkus E, Cardoso F. Recommendations for triage, prioritization and treatment of breast cancer patients during the COVID-19 pandemic. The Breast. 2020 08;52:8-16. https://doi. org/10.1016/j.breast.2020.04.006

12. Dignani MC, Costantini P, Salgueira C, Jordán R, Guerrini G, Valledor A, Herrera F, Nenna A, Mora C, Roccia-Rossi I, Stecher D, Carbone E, Laborde A, Efron E, Altclas J, Calmaggi A, Cozzi J. Pandemic 2009 Influenza A (H1N1) virus infection in cancer and hematopoietic stem cell transplant recipients; a multicenter observational study.. F1000Research. 2015 08 25;3:221. https://doi.org/10.12688/ f1000research.5251.2

13. Zhang $\mathrm{C}$, Wu Z, Li J, Zhao H, Wang G. Cytokine release syndrome in severe COVID-19: interleukin-6 receptor antagonist tocilizumab may be the key to reduce mortality. International Journal of Antimicrobial Agents. 2020 05;55(5):105954. https://doi.org/10.1016/j. ijantimicag.2020.105954

14. Shi Y, Wang Y, Shao C, Huang J, Gan J, Huang X, Bucci E, Piacentini M, Ippolito G, Melino G. COVID-19 infection: the perspectives on immune responses. Cell Death \& Differentiation. 202003 23;27(5):1451-1454. https://doi. org/10.1038/s41418-020-0530-3

15. Salari A, Shirkhoda M. COVID-19 pandemic \& head and neck cancer patients management: The role of virtual multidisciplinary team meetings. Oral Oncology. 2020 06;105:104693. https://doi.org/10.1016/j. oraloncology.2020.104693

16. Rodler S, Apfelbeck M, Stief C, Heinemann V, Casuscelli J. Lessons from the coronavirus disease 2019 pandemic: Will virtual patient management reshape uro-oncology in Germany?. European Journal of Cancer. 2020 06;132:136- 
140. https://doi.org/10.1016/j.ejca.2020.04.003

17. Skrajnowska D, Bobrowska-Korczak B. Role of Zinc in Immune System and Anti-Cancer Defense Mechanisms. Nutrients. 201909 22;11(10):2273. https://doi.org/10.3390/ nu11102273

18. Maggini S, Pierre A, Calder P. Immune Function and Micronutrient Requirements Change over the Life Course. Nutrients. 2018 Oct 17;10(10):1531. https://doi. org/10.3390/nu10101531

19. Haase H, Rink L. The immune system and the impact of zinc during aging. Immunity \& Ageing. 200906 12;6(1). https://doi.org/10.1186/1742-4933-6-9

20. Hojyo S, Fukada T. Roles of Zinc Signaling in the Immune System. Journal of Immunology Research. 2016;2016:1-21. https://doi.org/10.1155/2016/6762343

21. Sapkota M, Knoell DL. Essential Role of Zinc and Zinc Transporters in Myeloid Cell Function and Host Defense against Infection. Journal of Immunology Research. 2018 Oct 17;2018:1-8. https://doi.org/10.1155/2018/4315140

22. Gombart AF, Pierre A, Maggini S. A Review of Micronutrients and the Immune System-Working in Harmony to Reduce the Risk of Infection. Nutrients. 202001 16;12(1):236. https:// doi.org/10.3390/nu12010236

23. Chen Y, Feng H, Jeng S. Zinc Supplementation Stimulates Red Blood Cell Formation in Rats. International Journal of Molecular Sciences. 201809 18;19(9):2824. https://doi. org/10.3390/ijms19092824

24. Akram M, Iqbal M, Daniyal M, Khan AU. Awareness and current knowledge of breast cancer. Biological Research. 2017 Oct 02;50(1). https://doi.org/10.1186/s40659-0170140-9

25. Bhattacharya PT, Misra SR, Hussain M. Nutritional Aspects of Essential Trace Elements in Oral Health and Disease: An Extensive Review. Scientifica. 2016;2016:1-12. https://doi. org/10.1155/2016/5464373

26. Mohammad MK, Zhou Z, Cave M, Barve A, McClain CJ. Zinc and Liver Disease. Nutrition in Clinical Practice. 2012 02;27(1):8-20. https://doi.org/10.1177/0884533611433534

27. John E, Laskow TC, Buchser WJ, Pitt BR, Basse PH, Butterfield LH, Kalinski P, Lotze MT. Zinc in innate and adaptive tumor immunity. Journal of Translational Medicine. 2010;8(1):118. https://doi.org/10.1186/1479-5876-8-118

28. Al Bitar, Gali-Muhtasib. The Role of the Cyclin Dependent Kinase Inhibitor p21cip1/waf1 in Targeting Cancer: Molecular Mechanisms and Novel Therapeutics. Cancers. 201909 30;11(10):1475. https://doi.org/10.3390/ cancers 11101475

29. Mortaz E, Tabarsi P, Mansouri D, Khosravi A, Garssen J, Velayati A, Adcock IM. Cancers Related to Immunodeficiencies: Update and Perspectives. Frontiers in Immunology. 201609 20;7. https://doi.org/10.3389/ fimmu.2016.00365

30. Wang Y, Sun Z, Li A, Zhang Y. Association between serum zinc levels and lung cancer: a meta-analysis of observational studies. World Journal of Surgical Oncology. 201905 06;17(1). https://doi.org/10.1186/s12957-019-1617-5

31. Ho E, Song Y. Zinc and prostatic cancer. Current Opinion in Clinical Nutrition and Metabolic Care. 2009 Nov;12(6):640645. https://doi.org/10.1097/mco.0b013e32833106ee

32. Ho E. Zinc deficiency, DNA damage and cancer risk. The Journal of Nutritional Biochemistry. 2004 Oct;15(10):572578. https://doi.org/10.1016/j.jnutbio.2004.07.005

33. Derouiche S, Kechrid Z. Influence of calcium supplements on zinc status, carbohydrate metabolism and the liver activity of detoxifying glutathione enzymatic system in alloxan induced diabetic rats. J Exp Biol Agr Sci. 2013;1(6):424-9.
34. Cabrera ÁJR. Zinc, aging, and immunosenescence: an overview. Pathobiology of Aging \& Age-related Diseases. 2015 01;5(1):25592. https://doi.org/10.3402/pba.v5.25592

35. Derouiche S, Abbas K, Djermoune M, Ben-Amara S, Kechrid Z. The effects of copper supplement on zinc status, enzymes of zinc activities and antioxidant status in alloxaninduced diabetic rats fed on zinc over-dose diet. Int J Nutr Metab. 2013;5(5):82-7.

36. Prasad AS. Discovery of Human Zinc Deficiency: Its Impact on Human Health and Disease. Advances in Nutrition. 2013 03 01;4(2):176-190. https://doi.org/10.3945/an.112.003210

37. Jarosz M, Olbert M, Wyszogrodzka G, Młyniec K, Librowski T. Antioxidant and anti-inflammatory effects of zinc. Zincdependent NF- $\kappa$ B signaling. Inflammopharmacology. 2017 01 12;25(1):11-24. https://doi.org/10.1007/s10787-017$0309-4$

38. Prasad AS, Bao B. Molecular Mechanisms of Zinc as a ProAntioxidant Mediator: Clinical Therapeutic Implications. Antioxidants. 201906 06;8(6):164. https://doi.org/10.3390/ antiox 8060164

39. Prasad AS. Zinc is an Antioxidant and Anti-Inflammatory Agent: Its Role in Human Health. Frontiers in Nutrition. 201409 01;1. https://doi.org/10.3389/fnut.2014.00014

40. Read SA, Obeid S, Ahlenstiel C, Ahlenstiel G. The Role of Zinc in Antiviral Immunity. Advances in Nutrition. 2019 04 22;10(4):696-710. https://doi.org/10.1093/advances/ nmz013

41. Maares M, Haase H. A Guide to Human Zinc Absorption: General Overview and Recent Advances of In Vitro Intestinal Models. Nutrients. 202003 13;12(3):762. https:// doi.org/10.3390/nu12030762

42. Price CT, Langford JR, Liporace FA. Essential Nutrients for Bone Health and a Review of their Availability in the Average North American Diet. The Open Orthopaedics Journal. 201204 05;6(1):143-149. https:// doi.org/10.2174/1874325001206010143

43. Gasmi A, Noor S, Tippairote T, Dadar M, Menzel A, Bjørklund G. Individual risk management strategy and potential therapeutic options for the COVID-19 pandemic. Clinical Immunology. 2020 06;215:108409. https://doi. org/10.1016/j.clim.2020.108409

44. Samir D, Kaouther A, Djermoune M. Changes in metabolism of Zinc and carbohydrate and testis oxidative stress of diabetic rats fed zinc-over dose diet. Int J Biol Med Res. 2017;8(3):6041-5.

45. Zeba AN, Sorgho H, Rouamba N, Zongo I, Rouamba J, Guiguemdë RT, Hamer DH, Mokhtar N, Ouedraogo J. Major reduction of malaria morbidity with combined vitamin $\mathrm{A}$ and zinc supplementation in young children in Burkina Faso: a randomized double blind trial. Nutrition Journal. 200801 31;7(1). https://doi.org/10.1186/1475-2891-7-7

46. Laghari GS, Hussain Z, Taimur M, Jamil N. Therapeutic Role of Zinc Supplementation in Children Hospitalized with Pneumonia. Cureus. 201904 16; https://doi.org/10.7759/ cureus. 4475

47. WHO. Zinc supplementation to improve treatment outcomes among children diagnosed with respiratory infections. 2011..

48. High K. Nutritional Strategies to Boost Immunity and Prevent Infection in Elderly Individuals. Clinical Infectious Diseases. 2001 Dec;33(11):1892-1900. https://doi. org/10.1086/324509

49. Hemilä H, Fitzgerald JT, Petrus EJ, Prasad A. Zinc Acetate Lozenges May Improve the Recovery Rate of Common Cold Patients: An Individual Patient Data Meta-Analysis. Open Forum Infectious Diseases. 2017;4(2). https://doi. org/10.1093/ofid/ofx059 
50. Roth DE, Richard SA, Black RE. Zinc supplementation for the prevention of acute lower respiratory infection in children in developing countries: meta-analysis and metaregression of randomized trials. International Journal of Epidemiology. 201002 15;39(3):795-808. https://doi. org/10.1093/ije/dyp391

51. Gupta M, Mahajan VK, Mehta KS, Chauhan PS. Zinc Therapy in Dermatology: A Review. Dermatology Research and Practice. 2014;2014:1-11. https://doi. org/10.1155/2014/709152

52. Rao G, Rowland K. PURLs: Zinc for the common cold--not if, but when. J Fam Pract. 2011;60(11):669-71.

53. Cai S, Gong J, Yang J, Wang J. Anemia following zinc treatment for Wilson's disease: a case report and literature review. BMC Gastroenterology. 201907 09;19(1). https:// doi.org/10.1186/s12876-019-1038-5

\section{(c) (i) ()}

This work is licensed under a Creative Commons AttributionNon Commercial 4.0 International License. 